\title{
Three-dimensional Investigations of Non-metallic Inclusions in Stainless Steels before and after Machining
}

\author{
Hongying DU, ${ }^{*}$ Andrey Vladimirovich KARASEV and Pär Göran JÖNSSON \\ Department of Materials Science and Engineering, KTH Royal Institute of Technology, Brinellvägen 23, Stockholm, SE-100 44 \\ Sweden.
}

(Received on November 13, 2020; accepted on January 26, 2021; J-STAGE Advance published date: March 31, 2021)

\begin{abstract}
The focus of this study is to investigate non-metallic inclusions (NMIs) in stainless steels before (in steel samples) and after machining (in steel chips). In this study, the electrolytic extraction (EE) technique was used to extract non-metallic inclusions from steel samples. This makes it possible to investigate NMIs on film filters as three-dimensional objects by using SEM. The characteristics of NMIs in steel and chips have been systematically investigated and compared. Based on the results, it was found that the morphology of NMls was significantly changed after machining. Overall, three different main shapes of NMls were found: 1) a similar shape, 2) a stretched shape, and 3) a brittlely fractured shape. Furthermore, the degree of deformation of $\mathrm{MnS}$ and soft oxide NMls in different zones of the chips depends on the distances from the contact zone of the tool and the chip. The total areas of MnS and soft oxides in the secondary deformation zone were increased by up to 2-3 times compared to that of the reference steel sample. This study also shows the advantages of the EE method in investigating NMls in chips compared to using the conventional two-dimensional investigations of NMls on the polished metal surface.
\end{abstract}

KEY WORDS: stainless steel; chip; non-metallic inclusions; electrolytic extraction; secondary deformation zone.

\section{Introduction}

Machining of materials represents an important process and a major part of the entire manufacturing cost. Except for the own mechanical properties of materials, non-metallic inclusions (NMIs) also play a significant role with respect to the machinability of steels. Thus, works aimed at the evaluation of the effect of NMIs on machining have drawn a lot of attention. The different properties of NMIs, such as the hardness and thermal expansions, will have different effects during the machining of materials. For example, some quite hard inclusions in the metal matrix will scratch the tool surface during the machining process and decrease the tool life through abrasion. ${ }^{1,2)}$ However, some NMIs, like sulfides and Ca-treated oxides, have been found to be beneficial for extending the tool life and decreasing the consumption of power and lower the manufacturing cost. ${ }^{2-7)}$ The mechanisms responsible for machinability improvements by these NMIs can be summarized in two main ways: 1) NMIs are beneficial for chip crack during the chip formation period by acting as a source of stress concentrations, which decrease the necessary cutting force, as well as the mechanical wear

\footnotetext{
* Corresponding author: E-mail: hongying@kth.se
}

of tools by chips and 2) NMIs form a tool protection layer on the surface of the cutting tool part being in contact with the chip, which reduces the chemical and mechanical tool wear and extends the tool life. ${ }^{7-12)}$ It is apparent that different inclusions can have different (negative or positive) effects on the steel chip breakability (as concentrators of additional stress for easer destruction of the steel matrix during machining) and the tool protection (forming a soft layer for protection of the tool surface). Therefore, the effects of different inclusions on these machining parameters should be evaluated separately in different machining zones.

To evaluate the role of non-metallic inclusions on the machining, various investigations of NMIs have been carried out by using different approaches and methods. For example, some researchers ${ }^{1,6,10,13)}$ studied the machinability of different steels depending on the characteristics of related NMIs in those steels. Furthermore, investigations of the remaining elements on the surface of the cutting tools after machining have also been a good way to get information about the effect of NMIs on tool conditions. For example, based on the investigation of the surface and the cross-section of the cutting tools, the formation of the tool protection layer by NMIs has been described by several 
groups. ${ }^{3-5,7,14-16)}$ Here, the X-ray energy dispersive spectroscopy (EDS) or X-ray photoelectron spectroscopy (XPS) and EPMA results have sufficiently confirmed the role of inclusions containing $\mathrm{Ca}, \mathrm{Mn}, \mathrm{S}, \mathrm{Al}$, and $\mathrm{Si}$ during machining. ${ }^{3-5,7,14,15)}$ In addition, transmission electron microscopy (TEM) has also been applied to investigate the structure and composition of the built-up layer on coated tools by Larsson et al. ${ }^{16)}$

Most of the studies mentioned above did not focus on a more in-depth investigation of the chip during machining of steels related to the non-metallic inclusion characteristics in metals. Only a few publications have directly investigated the NMIs in the chips after machining. ${ }^{10,17)}$ This can be explained by the fact that it is challenging to investigate significantly deformed/stretched NMIs (especially inclusions like $\mathrm{MnS}$ ) near the cutting zone on polished chip surfaces by using conventional two-dimensional (2D) methods. For instance, Nordgren and Melander ${ }^{17)}$ have investigated the deformation behavior of different non-metallic inclusions on a polished cross-section in the secondary deformation zone of chips, by using scanning electron microscopy (SEM). However, it was found that soft inclusions like $\mathrm{MnS}$ in the secondary deformation zone were so extremely deformed that they were hard to be found near or on the chip surface, even with this precise SEM method. Only occasionally some $\mathrm{MnS}$ inclusions thicker than these extremely thin particles could be found. In this case, the aspect ratio (ratio between length and width of observed inclusion) could be used as a factor to evaluate the malleability/deformability of NMIs.

Previous researchers ${ }^{18-20)}$ have established the significant benefits of three-dimensional (3D) investigations of NMIs having complex morphologies (such as largely deformed $\mathrm{MnS}$ ) and clusters by using electrolytic extraction (EE). Compared to the extraction methods by using acid and neutral aqueous electrolytes, the use of nonaqueous electrolytes shows its good reproducibility, especially with respect to dissolution loss of chemically unstable inclusions, when a suitable nonaqueous electrolyte for specific inclusion phases is selected. ${ }^{21-23)}$ Moreover, it was reported ${ }^{22)}$ that the $10 \% \mathrm{AA}$ electrolyte can be successfully used for extraction of complex non-metallic inclusions contained $\mathrm{Al}_{2} \mathrm{O}_{3}, \mathrm{SiO}_{2}$, $\mathrm{CaO}, \mathrm{MgO}, \mathrm{TiO}_{\mathrm{x}}, \mathrm{MnS}$, and $\mathrm{CaS}$ without dissolution loss of inclusion components during extractions. During the electrolytic dissolution of the steel matrix, more stable nonmetallic inclusions can be extracted from steel. Then, after filtration, these inclusions can be investigated as 3D objects on a surface of film filter by using SEM in combination with EDS. However, studies of NMIs in chips after machining obtained by this EE method have not been reported up to now.

The motivation of this study is to investigate the characteristics of different non-metallic inclusions in Ca-treated stainless steels before machining as well as in different zones of the chips after machining, by using the electrolytic extraction technique. After extraction, the characteristics of NMIs in steel and chips, for instance, the morphology, size, number, and composition, are systematically investigated and compared. Therefore, based on the comparison results of NMIs' behavior at different locations, the effects of different NMIs on chip breakability and tool wear of the given stainless steel during machining are studied.

\section{Experimental}

\subsection{Workpiece Materials and Chips}

The workpiece material is a rolled bar of a Ca-treated $316 \mathrm{~L}$ stainless steel $(316 \mathrm{~L}+\mathrm{Ca})$, in which the $\mathrm{Ca}$ addition was done at the end of the ladle refining. The CaSi wire addition in the melt was done to obtain a modification of oxide inclusions to improve the machinability of the steel after rolling. The bar used in this study has a $121 \mathrm{~mm}$ diameter. The contents of the main elements in investigated steel are the following (in mass\%): C 0.01, Si 0.46, Mn 1.58, Cr 16.86, Ni 11.14, Mo 2.0, N 0.06, S 90 ppm, O 59 ppm, Ca 28 ppm, Al 40 ppm.

The orthogonal cutting process was carried out by using the tool TPUN 1603042025 (Chemical vapor deposition (CVD) coating by $\left.\mathrm{Ti}(\mathrm{C}, \mathrm{N})+\mathrm{Al}_{2} \mathrm{O}_{3}+\mathrm{TiN}\right)$ at a speed of 250 $\mathrm{m} / \mathrm{min}$ without any cutting fluid. The feed rate and cutting depth are $0.25 \mathrm{~mm} / \mathrm{rev}$ and $3 \mathrm{~mm}$, respectively. Typical long chips obtained during the cutting process were used for the investigation of non-metallic inclusions. In addition, a reference steel sample (Sample A) from the original bar before the machining was used for the evaluation of the initial characteristics of NMIs.

\subsection{Electrolytic Extraction and Investigation of Inclu- sions in Steel and Chips}

The electrolytic extraction process was used to evaluate the characteristics of NMIs in the reference steel sample and chips. As the previous study ${ }^{24)}$ shows, a EE performed with the nonaqueous electrolytes named 10\% AA (10\% acetylacetone - $1 \%$ tetramethylammonium chloride methanol) works well with Ca-containing inclusions in a normal-size Ca-treated 316L stainless steel sample. Thus, similar EE conditions except a much shorter extraction time were performed on steel chips in this study. The extraction process was performed during 30-150 minutes using the following electric parameters: a voltage of 2.9-3.5 V, an electric current of 40-50 mA, and an electric charge of 500 coulombs for the reference metal and 80-200 coulombs for the chip samples. After electrolytic extraction, the inclusions extracted from the metal surface were collected on a surface of the filter by filtration of the electrolyte solution through a polycarbonate (PC) membrane film filter with an open pore size of $0.4 \mu \mathrm{m}$. Thereafter, the extracted inclusions were investigated on the surface of film filters by using scanning electron microscopy. The compositions of inclusions were determined by using energy dispersive spectroscopy (EDS), which is connected to the SEM.

Three pieces were cut in succession from the same long chip. These were electrolytically extracted by using different electric charges to dissolve the chip sample to different depths. To extract the aimed zone of the chip, one side of the chip sample (Side 2, which is opposite to the chip surface in contact with the tool) was covered by an unconductive hot melt glue, as schematically shown in Fig. 1. This unconductive glue layer was used for the protection of Side 2 from the electrolytic dissolution of the steel chip from both sides to avoid of mixing of NMIs extracted from different chip zones. The main focus area in chips for investigation in 
(a)

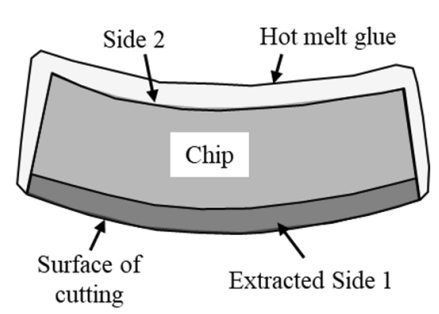

(b)

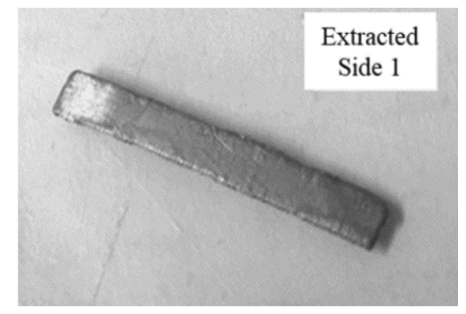

(c)

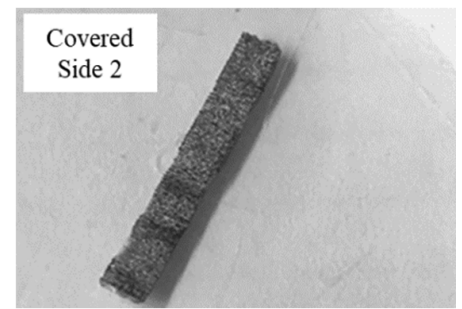

Fig. 1. A schematic illustration of the chip sample used for extraction (a) and photographs of extracted (b) and covered (c) sides of the chip sample after electrolytic extraction.

(a)

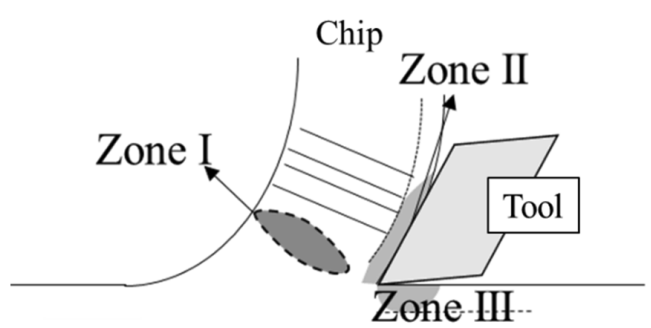

Steel (b)

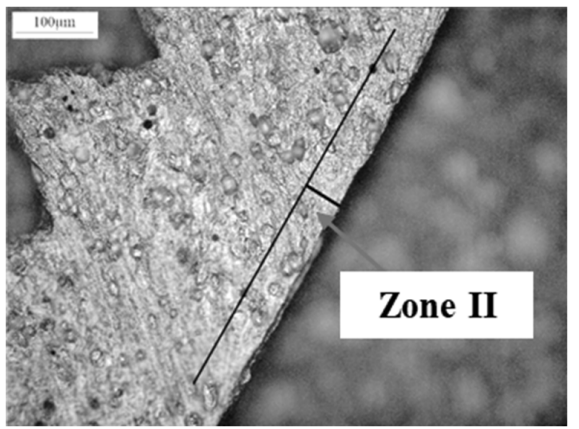

Fig. 2. A schematic illustration (a) and a light optical microscopy (LOM) image (b) of the secondary deformation zone.

this study was the secondary deformation zone, which is shown in Fig. 2.

Since the secondary deformation zone in the investigated chips is around $50 \mu \mathrm{m}$ (Fig. 2(b)), the depths of dissolved steel layer $\left(D_{\text {dis }}\right)$ from Side 1 of chips were approximately $65 \mu \mathrm{m}$ (Sample H1), $51 \mu \mathrm{m}$ (Sample H2), and $34 \mu \mathrm{m}$ (Sample H3). One more sample (Sample T) was electrolytically extracted by using another side (Side 2, which is opposite to the chip surface in contact with the tool) while the cutting side (Side 1) was covered. The weight of the dissolved metal for chip samples varied from 0.019 to 0.037 $\mathrm{g}$, depending on the electric charge and dissolved depth of the chip. Table 1 gives more detailed information about the investigated samples and the cutting parameters used in the experiments.

If a homogeneity of NMI distribution on film filters after electrolytic extraction was confirmed by visual SEM observations, the inclusion characteristics (such as morphology, composition, size, and number) were systematically investigated. To quantitatively evaluate the degree of deformation of NMIs by using the aspect ratio value $(A R=l / w)$, the length $(l)$, width $(w)$, and total surface area $\left(A_{N M I}\right)$ of every individual investigated NMI was measured automatically on the photos obtained by SEM by using the Image-J image analysis software. Then, the surface area per volume $\left(A_{v}\right)$ and the average surface area of investigated inclusions $\left(A_{\text {ave }}\right)$ were calculated by using the following equations:

$$
A_{v(\text { Type } i)}=\frac{\sum A_{N M I(\text { Type } i)}}{\frac{W_{d i s}}{\rho} \times \frac{A_{\text {obs }}}{A_{\text {fil }}}}
$$

Table 1. Main parameters used in the electrolytic extractions and SEM investigations of non-metallic inclusions (NMIs) in different samples.

\begin{tabular}{cccrccc}
\hline Sample & $\begin{array}{c}\mathrm{D}_{\text {dis }} \\
{[\mu \mathrm{m}]}\end{array}$ & $\begin{array}{c}\mathrm{W}_{\text {dis }} \\
{[\mathrm{g}]}\end{array}$ & $\begin{array}{c}\mathrm{A}_{\text {fil }} \\
{\left[\mathrm{mm}^{2}\right]}\end{array}$ & $\begin{array}{c}\mathrm{A}_{\text {obs }} \\
{\left[\mathrm{mm}^{2}\right]}\end{array}$ & $\begin{array}{c}\text { Number of } \\
\text { observed } \\
\text { NMIs, } n\end{array}$ & $\begin{array}{c}\text { Size range } \\
{[\mu \mathrm{m}]}\end{array}$ \\
\hline $\mathrm{A}$ & 85 & 0.0935 & 1200 & 0.898 & 180 & $3-124$ \\
$\mathrm{H} 1$ & 65 & 0.0369 & 1200 & 0.675 & 96 & $2-49$ \\
$\mathrm{H} 2$ & 51 & 0.0329 & 80 & 0.089 & 219 & $2-44$ \\
$\mathrm{H} 3$ & 34 & 0.0258 & 80 & 0.056 & 142 & $2-32$ \\
$\mathrm{~T}$ & 47 & 0.0191 & 80 & 0.045 & 100 & $2-46$ \\
\hline
\end{tabular}

$$
A_{\text {ave }(\text { Type } i)}=\frac{\sum A_{\text {NMI(Type } i)}}{n_{(\text {Type } i)}}
$$

where $A_{N M I(T y p e ~ i)}$ is the total surface area of a non-metallic inclusion of Type $i$ investigated on the filter, $n_{(\text {Type } i)}$ is the number of Type $i$ inclusions, $W_{d i s}$ is the weight loss of the metal and chip sample during EE, and $\rho$ is the metal density ( $=0.0078 \mathrm{~g} / \mathrm{mm}^{3}$ in this study), $A_{\text {fil }}$ is the whole filtration area of a film filter with collected inclusions ( $=80$ or 1200 $\mathrm{mm}^{3}$ depending on samples), $A_{o b s}$ is the total observed area of the film filter used for the image analysis. When calculating $A_{\text {NMI(Type } i)}$, two times of the measured area of one NMI on the filter were considered as the total surface area of that inclusion. Moreover, the non-metallic inclusions were also investigated on the cross-section (2D method) surface of some chips for comparison to the results obtained from the 3D investigations after electrolytic extraction of chip samples. 


\section{Results and Discussions}

\subsection{Classification of Non-metallic Inclusions in Steel Matrix and Chips}

The main non-metallic inclusions found in the original steel samples were classified in the following types: i) $\mathrm{MnS}$ (including pure $\mathrm{MnS}$ and some oxy-sulfides having oxides as cores), ii) soft oxides (SO, which were deformed during rolling, having a composition of $\mathrm{CaO}-\mathrm{SiO}_{2}-\mathrm{Al}_{2} \mathrm{O}_{3}-$ $\mathrm{MgO}-\mathrm{TiO}_{\mathrm{x}}$ between gehlenite and anorthite), and iii) hard oxides (HO, which were not deformed during rolling, having a composition of $\mathrm{CaO}-\mathrm{SiO}_{2}-\mathrm{Al}_{2} \mathrm{O}_{3}-\mathrm{MgO}$ quite close to gehlenite), as shown in Table 2.

It should be pointed out that the observed $\mathrm{SO}$ and $\mathrm{HO}$ inclusions did not contain $\mathrm{CaS}$, due to the limited addition of $\mathrm{Ca}$ during the production of this steel grade.

By 2D investigations of inclusions on the cross-sections of the chip samples, some needle-like sulfides having a width of $\sim 0.1 \mu \mathrm{m}$ were found, as shown in Fig. 3. It indicated that an extra significant deformation of $\mathrm{MnS}$ inclu- sions occurred during the machining process. Furthermore, by these $2 \mathrm{D}$ investigations on the cross-section, no special oxides were found to be quite different from those present in the original steel samples.

The morphologies of non-metallic inclusions in the chips, observed by using 3D investigations after EE, were quite different in comparison to the original morphologies of NMIs in the steel before machining. This difference showed that the behavior of different non-metallic inclusions varied depending on their properties and the conditions of the cutting process. Based on the different morphologies, the observed NMIs can be divided mainly into the following three different groups: 1) Group I inclusions, whose shapes were similar to the original ones (maybe only a little additional deformation exists); 2) Group II - stretched inclusions, which were soft as a dough and were stretched out to form a quite thin film (Group II-a) or fragmented on small connected slices containing some holes or fissures (Group II-b); (3) Group III - brittlely fractured inclusions, which were compressed and crushed

Table 2. Classification of the inclusions observed in stainless steel and chip samples before and after the machining test.

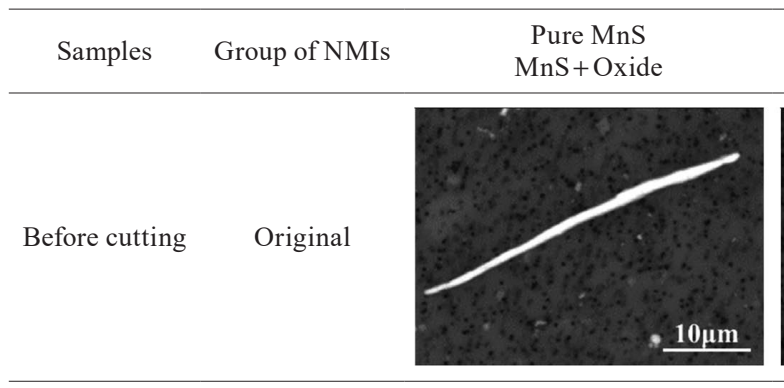
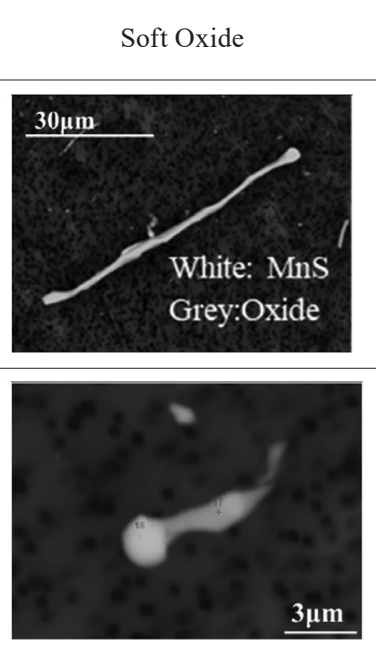

$\mathrm{Ca} \sim 50 \% \mathrm{Al} \sim 29 \%$

$\operatorname{Si\sim } 18 \% \mathrm{Mg} \sim 3 \%$

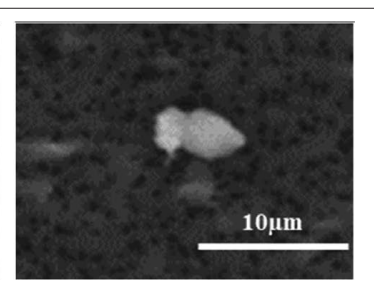

Not observed

Not observed

Not observed

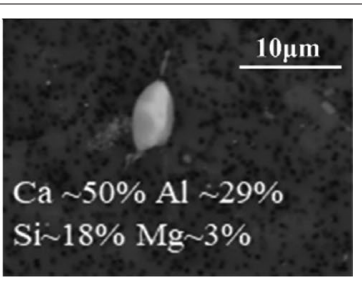

Group II-b

Brittlely fractured Group III
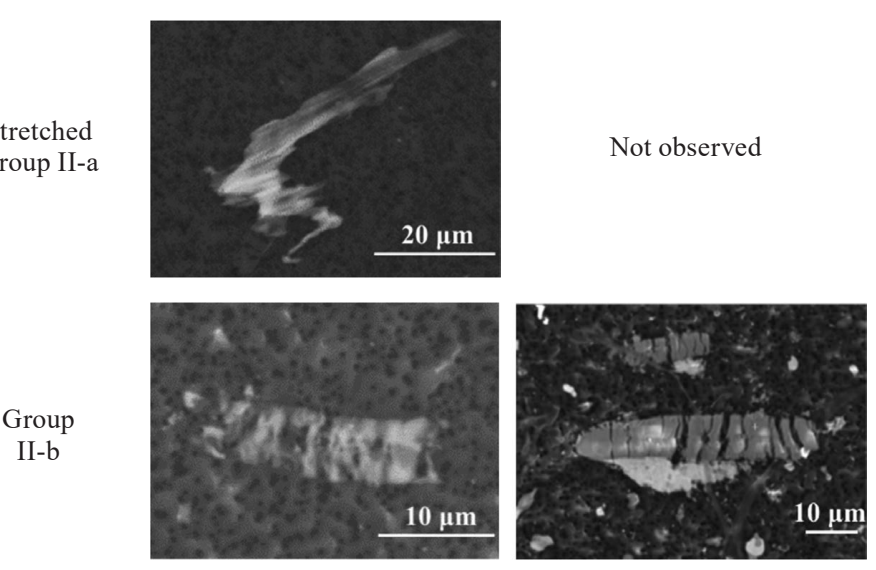

Stretched Group II-a
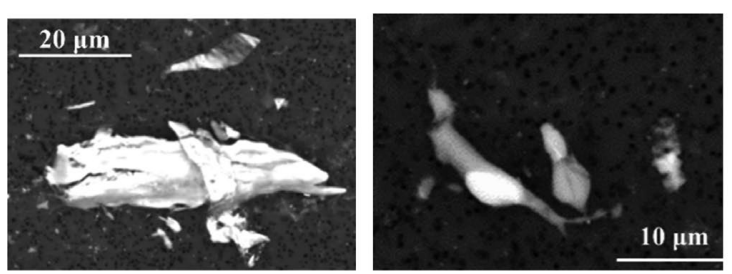

Ca $52 \%$ Al $29 \%$ Si $16 \% \mathrm{Mg} 3 \%$

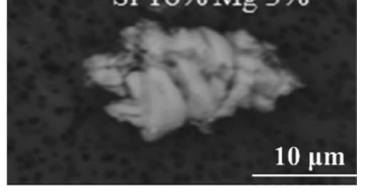


by the steel matrix during cutting and cracks were observed in the inclusions.

It should be pointed out that no stretched $\mathrm{HO}$ inclusions were found in any of the studied chip samples. This fact can be explained by the significant hardness of these inclusions, even at high temperatures in the cutting zone. It is apparent that the HO inclusions can keep their initial shape (Group I) or form Group III brittlely fractured inclusions at a stretched extreme deformation of the steel matrix during the chip formation and when being in contact with the cutting tools. However, the soft inclusions (such as MnS and SO) were observed as all groups of NMIs, including the stretched Group II inclusions.

Since the temperature in the contact zone of the chip formation and the tool is quite high (up to $900-1100^{\circ} \mathrm{C}^{25,26)}$ ),

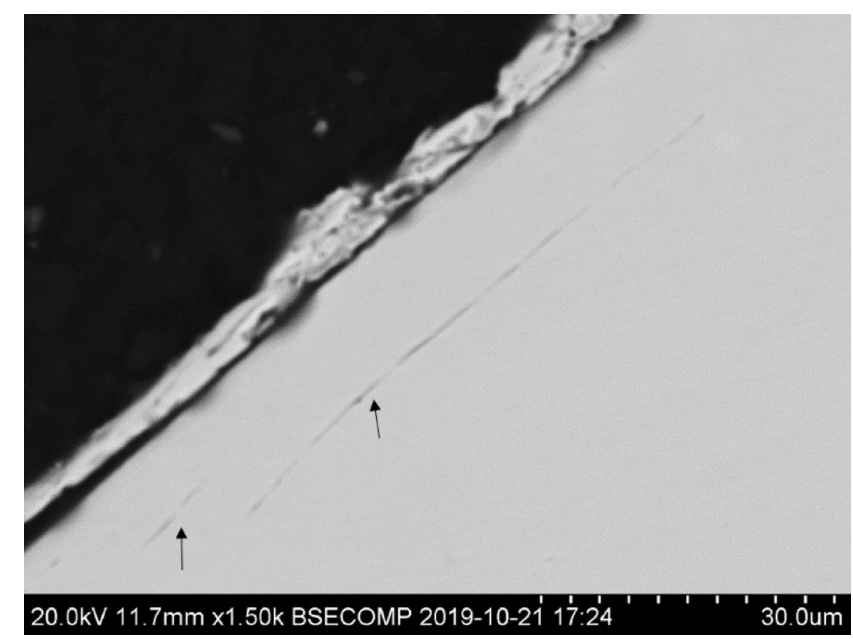

Fig. 3. Extremely deformed MnS inclusions (marked by arrows) found on the cross-section of steel chip. the soft inclusions elongated during rolling also showed a high degree of softness in the area near the rake face. The $\mathrm{MnS}$ inclusions were very soft and could easily be stretched to form a quite thin continuous film of Group II-a, as shown in Table 2. Some soft MnS inclusions even contained holes and fissures (Group II-b) during an extreme deformation, because the films of inclusions were too thin to deform to a more considerable degree. The SO inclusions didn't have the same deformability as the sulfides described above in this temperature range. They were also stretched to form a larger surface area, but contained some fissures (Group II-b). However, on the other side of the chips, which is not in contact with the rake face (Side 2), both brittlely fractured sulfides and SO inclusions could be found. It indicated that with the different temperature distribution in the chips, the non-metallic inclusions showed different behaviors. A more detailed discussion is given in the following sections.

It is apparent that the Group II inclusions on the polished cross-section of the metal surface look in most cases as very thin needle-like inclusions. Therefore, any investigations of these stretched film-like inclusions by using the common 2D method are very limited. This could explain why this stretched inclusion type was not detected in previous studies. ${ }^{10,17)}$ The realistic morphologies, size, and number of these stretched inclusions (Group II-a and II-b) were observed and measured by using the EE method. Moreover, it should be noted that these fragile film-like non-metallic inclusions were mostly not destroyed during the whole process of EE and filtration. This was confirmed by carrying out detailed investigations of the continuity of inclusions by using mapping of the main components in these inclusions, as shown in Fig. 4.
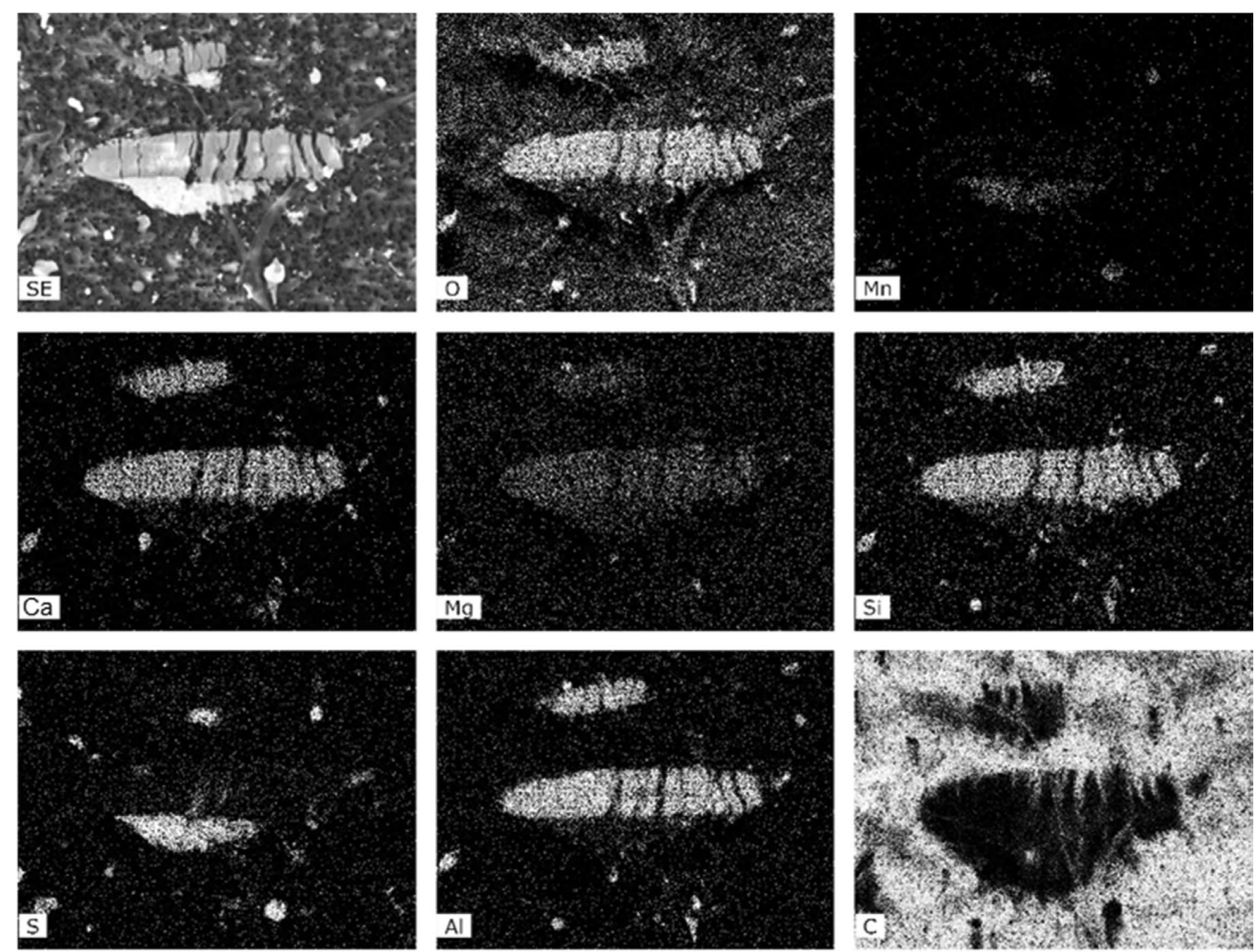

Fig. 4. Mapping of a SO Group II-b inclusions with fissures. 


\subsection{Characterization of Different NMIs in the Chips Depending on the Distance from the Cutting Sur- face}

For the characterization of different NMIs in the chips at different distances from the surface of cutting, three chip samples taken from the same long chip were dissolved to three different depths by using EE. The frequency of the different groups of inclusions were counted, compared, and summarized in Table $\mathbf{3}$ and Fig. 5 for different dissolution depths. It can be seen that the total percentage of sulfides (Group I + Group II) increases slightly from sample H1 $(\sim 50 \%)$ to $\mathrm{H} 3(\sim 58 \%)$. This can be explained by the increased number of broken pieces of sulfides close to the surface of cutting, which is due to the increased metal deformation. Although a $\mathrm{MnS}$ inclusion was quite soft in

Table 3. Distribution of different non-metallic inclusions in stainless steels depending on the dissolution depth of chip samples.

\begin{tabular}{|c|c|c|c|c|c|c|}
\hline Sample & $\begin{array}{l}\text { Dissolution } \\
\text { depth }(\mu \mathrm{m})\end{array}$ & $\begin{array}{l}\text { Class of } \\
\text { NMIs }\end{array}$ & $\begin{array}{l}\text { Group } \\
\text { I }\end{array}$ & $\begin{array}{l}\text { Group } \\
\text { II }\end{array}$ & $\begin{array}{l}\text { Group } \\
\text { III }\end{array}$ & Sum \\
\hline \multirow[t]{3}{*}{ A } & 85 & $\mathrm{MnS}$ & $54 \%$ & & & $54 \%$ \\
\hline & & $\mathrm{HO}$ & $22 \%$ & & & $22 \%$ \\
\hline & & $\mathrm{SO}$ & $24 \%$ & & & $24 \%$ \\
\hline \multirow[t]{3}{*}{ H1 } & 65 & $\mathrm{MnS}$ & $23 \%$ & $27 \%$ & $0 \%$ & $50 \%$ \\
\hline & & $\mathrm{HO}$ & $15 \%$ & $0 \%$ & $10 \%$ & $25 \%$ \\
\hline & & $\mathrm{SO}$ & $23 \%$ & $2 \%$ & $0 \%$ & $25 \%$ \\
\hline \multirow[t]{3}{*}{$\mathrm{H} 2$} & 51 & $\mathrm{MnS}$ & $16 \%$ & $38 \%$ & $0 \%$ & $54 \%$ \\
\hline & & $\mathrm{HO}$ & $16 \%$ & $0 \%$ & $9 \%$ & $25 \%$ \\
\hline & & $\mathrm{SO}$ & $14 \%$ & $7 \%$ & $0 \%$ & $21 \%$ \\
\hline \multirow[t]{3}{*}{$\mathrm{H} 3$} & 34 & $\mathrm{MnS}$ & $10 \%$ & $48 \%$ & $0 \%$ & $58 \%$ \\
\hline & & $\mathrm{HO}$ & $15 \%$ & $0 \%$ & $7 \%$ & $22 \%$ \\
\hline & & $\mathrm{SO}$ & $10 \%$ & $10 \%$ & $0 \%$ & $20 \%$ \\
\hline \multirow[t]{3}{*}{$\mathrm{T}$} & 47 & $\mathrm{MnS}$ & $15 \%$ & $26 \%$ & $10 \%$ & $51 \%$ \\
\hline & & $\mathrm{HO}$ & $9 \%$ & $0 \%$ & $11 \%$ & $20 \%$ \\
\hline & & SO & $18 \%$ & $5 \%$ & $6 \%$ & $29 \%$ \\
\hline
\end{tabular}

a cutting zone, the largest stretch deformation of the steel matrix close to the surface of cutting could increase the possibility of breaking this sulfide. This would also explain the reason for a slight drop in the percentage of oxides in the H3 sample. It is apparent that a significant increase of the percentage of stretched inclusions (Group II) was obtained for soft inclusions (from $27 \%$ to $48 \%$ for sulfides and from $2 \%$ to $10 \%$ for $\mathrm{SO}$ ) from sample $\mathrm{H} 1$ to sample $\mathrm{H} 3$ when the sample was taken close to the side near the rake face of the tool. Simultaneously, the percentage of similar inclusions (Group I) decreased for these two types of inclusions from $\sim 23 \%$ to $\sim 10 \%$. However, the percentage of HO inclusions (Groups I and III) remained almost stable in all samples $\mathrm{H} 1, \mathrm{H} 2$, and $\mathrm{H} 3$.

The area of non-metallic inclusions was also determined to study the deformation rate of different inclusions in various deformation zones. As shown in Fig. 6(a), the average area $\left(A_{\text {ave }}\right)$ of sulfides is the largest in sample $\mathrm{H} 1$ with a dissolution depth of $65 \mu \mathrm{m}$. Then, the average area of sulfide NMIs decreases significantly from sample H1 $\left(114 \mu \mathrm{m}^{2}\right)$ to $\mathrm{H} 3\left(64 \mu \mathrm{m}^{2}\right)$. This phenomenon can be explained by the previous statement of the reason why the number of sulfides increases from $\mathrm{H} 1$ to $\mathrm{H} 3$. The total area of sulfides $\left(A_{v}\right)$ is the largest in sample H3 (as shown in Fig. 6(b)), which is due to that the largest deformation of the metal matrix took place in this zone. In addition, it should be pointed out that the total area of sulfides observed in the H1-H3 samples are more than 2-3 times larger compared to those in the reference A sample.

The HO inclusions also show some decrease in the average and total areas of NMIs from sample H1 to sample H3. It may be explained by the fact that the $\mathrm{HO}$ inclusions might be broken, and due to that, some parts of the broked inclusions can be removed from a chip surface during cutting. The percentages of $\mathrm{HO}$ inclusions in $\mathrm{H} 1, \mathrm{H} 2$, and $\mathrm{H} 3$ are quite similar. Since the HO inclusions on the chip surface can more easily fall out from the matrix during an extreme cutting deformation, the characteristics of inclusions (such as $A_{\text {ave }}$ and $A_{v}$ ) in the sample with a shorter dissolution depth (H3) will also be affected more by the removed inclusions.

As follows from Fig. 6, the total area of SO inclusions

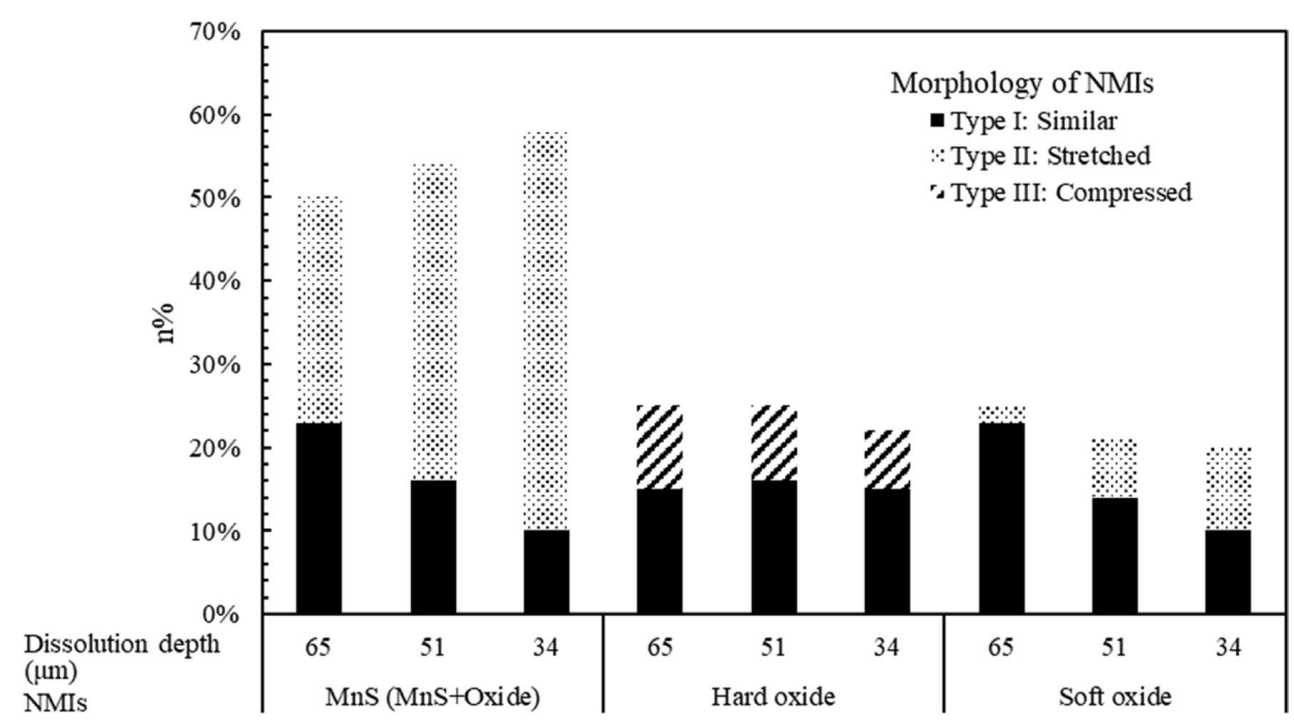

Fig. 5. Distributions of different types of non-metallic inclusions as a function of the dissolution depth during EE. 
(a)

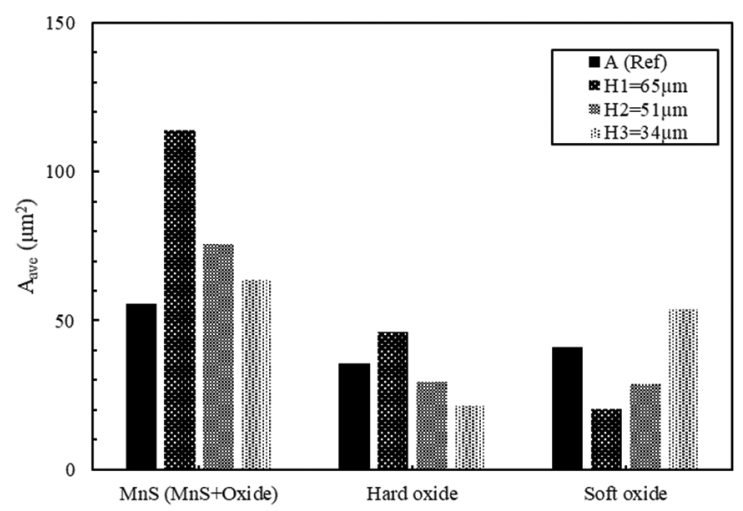

(b)

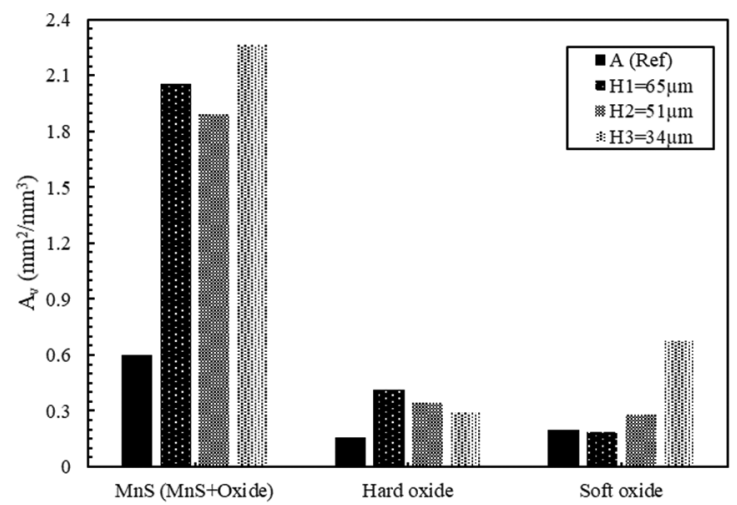

Fig. 6. Areas of different types of non-metallic inclusions as a function of the dissolution depth: (a) average area of inclusions $\left(A_{\text {ave }}\right)$ and (b) total area of inclusions per $\mathrm{mm}^{3}\left(A_{v}\right)$.

(a)

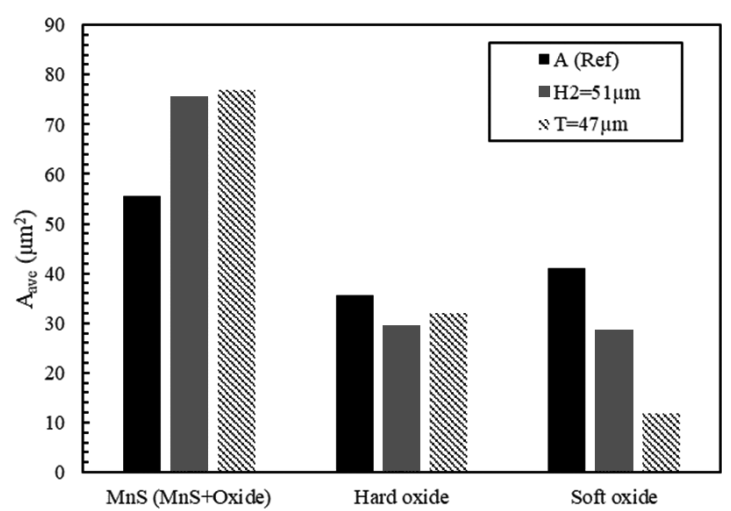

(b)

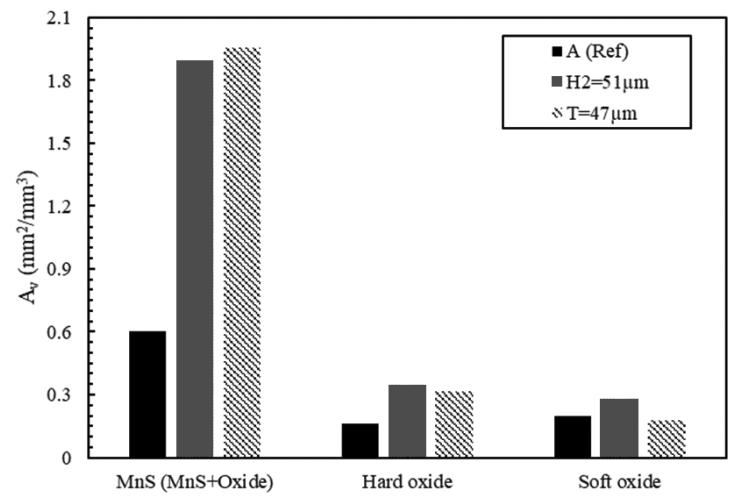

Fig. 7. Areas of different non-metallic inclusions in reference steel sample and on different sides of chips: (a) average area of inclusions $\left(A_{\text {ave }}\right)$ and (b) total area of inclusions per $1 \mathrm{~mm}^{3}\left(A_{v}\right)$.

increased significantly (2-3 times) from the H1 sample to the H3 sample. These results indicated that SO inclusions are more easily deformed near the contact surface of chips, where the largest deformations and temperatures are obtained. As a result, the total area of soft oxide inclusions observed in sample $\mathrm{H} 3$ is about three times larger compared to that in the reference A sample.

With different distances from the contact zone of the tool and the chip, various NMIs have different behaviors depending on the deformation and temperature of the steel matrix at different distances from the contact zone of the chip and the tool used during machining. As a result, the frequencies and surface areas (average and total areas) of different types of inclusions also changed.

\subsection{Characterization of Different NMIs on Different Sides of Chips}

The non-metallic inclusions on the other side (Side 2) of the chips (Sample T) were also investigated by using EE with a dissolution depth of $47 \mu \mathrm{m}$. The samples $\mathrm{T}$ and $\mathrm{H} 2$ having almost similar dissolution depths were used for a comparison of the behavior of various NMIs on the different sides of the chips. The frequencies of different inclusions are given in Table 3. It can be seen that the Group III brittlely fractured sulfides $(\sim 10 \%)$ and SO $(\sim 6 \%)$ were found in sample T. Many of them consist of broken pieces. On the other hand, the frequencies of the stretched sulfides (Group II-b) decreased significantly from $38 \%$ in the $\mathrm{H} 2$ sample to $26 \%$ in the T sample. A decreased frequency was also observed for stretched SO inclusions from $7 \%$ to $5 \%$. It can be explained by the lower temperature of the metal matrix on Side 2 of the chip compared to Side 1. It implies that most of the SO inclusions were not deformed and that they, therefore, behave as rigid particles found on Side 2 of the sample $\mathrm{T}$ at the given deformation and temperature ranges.

The average and total areas of different non-metallic inclusions of the reference steel sample (Sample A) and chip samples $\mathrm{H} 2$ and $\mathrm{T}$ are compared in Fig. 7. It was found that the sulfides in sample $\mathrm{T}$ have similar average and total areas of inclusions compared to those detected in the $\mathrm{H} 2$ samples. But both of them were much larger (up to 3 times) compared to that in the reference steel sample. It means that, though the brittlely fractured sulfides were found in the chip sample $\mathrm{T}$ (Side 2), most of the sulfides were nevertheless deformed on the metal surface (Zone III in Fig. 2(a)) to a high degree up to 3 times of reference steel sample (similar as on Side 1 of the chip, Zone II in Fig. 2(a)) before the following chip formation.

The HO inclusions showed similar average and total areas 
in all compared samples. It indicates that the temperature and deformation did not result in any difference in the morphology of $\mathrm{HO}$ in these samples. The $\mathrm{SO}$ inclusions previously deformed in the $\mathrm{H} 1-\mathrm{H} 3$ sample showed a larger tendency to break in the $\mathrm{T}$ sample during a compression deformation of the metal matrix at a lower metal temperature compared to another side of the chip. As a result, the SO inclusions in the T sample have a significantly smaller average area and a similar total area compared to the $\mathrm{H} 2$ sample. It should be noted that the morphology of Group III SO inclusion was different from the Group III sulfides. No apparent high-degree deformations, as found for sulfides, were found in the brittlely fractured SO.

\subsection{Deformation of Different NMIs Depending on Metal Matrix Deformation and Temperature}

The cutting temperature in the chip during an orthogonal turning of a standard $316 \mathrm{~L}$ stainless steel with a $\mathrm{Ti}(\mathrm{C}, \mathrm{N})+\mathrm{Al}_{2} \mathrm{O}_{3}+\mathrm{TiN}$ coated tool has been predicted by Kara et $a{ }^{25)}$ by using an artificial neural network. A prediction of the Ca-treated $316 \mathrm{~L}$ stainless steel with a higher sulfur content compared to an ordinary $316 \mathrm{~L}$ stainless steel was also obtained by Saoubi and Chandrasekaran. ${ }^{26)}$ Here, these results were applied as a reference to compare the different NMIs' behavior at different locations. By the predicted digraph for the different cutting feeds and cutting speeds obtained by Kara et al., ${ }^{25)}$ for the case in this study, the highest temperature in the contact zone was predicted to have a value of $1066^{\circ} \mathrm{C}$ at a cutting speed of $250 \mathrm{~m} / \mathrm{min}$. Following the maximum temperature predicted by Saoubi and Chandrasekaran, the Ca-treated 316L stainless steel containing a higher amount of $\mathrm{S}(0.027 \%)$ was roughly $20^{\circ} \mathrm{C}$ lower compared to a standard $316 \mathrm{~L}$ stainless steel without a Ca-treatment containing a lower amount of $\mathrm{S}$ $(0.009 \%)$ when using a cutting speed of $180 \mathrm{~m} / \mathrm{min}$. Thus, values between 1040 to $1050^{\circ} \mathrm{C}$ could be expected as being the maximum temperature in the chip's contact zone at the tool surface. Furthermore, the temperature decreases dramatically along with the distance from the chip-tool contact length. The temperature on the opposite side of the chip could be less than one-third of the maximum temperature $\left(<350^{\circ} \mathrm{C}\right)$, according to the simulation results obtained by Kara et al. ${ }^{25)}$

As the temperature increases, the ductility of sulfides increases because the hardness continuously decreases with an increased temperature. So the hardness of pure $\mathrm{MnS}$ inclusions at $800^{\circ} \mathrm{C}$ is only $20 \%$ of that at room temperature. ${ }^{27)}$ On the other hand, it is reported that Si-containing inclusions, including oxide inclusions discussed in the present study, will first act as rigid particles at low temperatures but become soft at a narrow transition temperature range. ${ }^{27,28)}$ Then, at temperatures larger than the transition temperature, the Si-containing inclusions become highly ductile. Thus, a similar S shape tendency of the plasticity could be expected for Si-containing inclusions, as shown in Fig. 8. Since $\mathrm{HO}$ and $\mathrm{SO}$ inclusions have different melting temperatures $\left(1590^{\circ} \mathrm{C}\right.$ for gehlenite $\left(2 \mathrm{CaO} \cdot \mathrm{Al}_{2} \mathrm{O}_{3} \cdot \mathrm{SiO}_{2}\right)$ and $1555^{\circ} \mathrm{C}$ for anorthite $\left.\left(\mathrm{CaO} \cdot \mathrm{Al}_{2} \mathrm{O}_{3} \cdot 2 \mathrm{SiO}_{2}\right)\right)$ and hardnesses (HV 1200 (gehlenite) and HV850 (anorthite)), ${ }^{29)}$ SO inclusions have a lower transition temperature range compared to HO inclusions. This could explain the different behaviors of oxides at different temperature zone. The maximum temperature on the chip-tool surface in this study did not reach the transition temperature range for $\mathrm{HO}$ inclusions, so $\mathrm{HO}$ inclusions remain rigid in the whole chips. However, the maximum temperature in the chip's contact zone has reached the transition range for SO inclusions but has not exceeded it. Thus, the stretched SO inclusions of Group II-b were found only near the chip-tool surface, whereas SO inclusions of Group III were found on the other chip side. The results observed in the present study with respect to the deformation of sulfides and SO inclusions in the different zones of the chips are summarized in Table 4, based on the deformation and temperature conditions.

It was found that the film-like Group II-a sulfides can be formed mostly on the surface of the chips (Zone II, Fig. 2(a)) during machining by a high stretched deformation and a high temperature $\left(\sim 900-1050^{\circ} \mathrm{C}\right)$. The soft and ductile $\mathrm{MnS}$ can act as a solid lubricant at the interface between the tool and sliding workpiece during cutting. ${ }^{11)}$ It should be pointed out that the film-like SO did not form during the given cutting conditions, because the temperatures of metal on the surface of cutting was not high enough. High temperatures over the transition temperature range are necessary for the formation of film-like oxide inclusions. The fragmented stretched sulfides and soft oxide inclusions (Group II-b) were observed in the H1-H3 and $\mathrm{T}$ samples. The largest number of the Group II inclusions are observed in Sample H3 ( $\sim 58 \%$ from the total number of all group inclusions, dissolution depth $\left.D_{\text {dis }} \sim 34 \mu \mathrm{m}\right)$ and H2 $\left(45 \%, D_{\text {dis }} \sim 51 \mu \mathrm{m}\right)$. However, in samples H1 $\left(D_{\text {dis }} \sim 65\right.$ $\mu \mathrm{m}$ ) and $\mathrm{T}$ (Side 2, $D_{\text {dis }} \sim 47 \mu \mathrm{m}$ ), the values were only 29 and $31 \%$, respectively. Therefore, it may safely be suggested that the Group II-b inclusions were fragmented during a stretched deformation of the chip metal (Side 1) at the lower temperature range (about $600-900^{\circ} \mathrm{C}$ for $\mathrm{MnS}$ and $900-1050^{\circ} \mathrm{C}$ for $\mathrm{SO}$ ) in the secondary deformation zone. These fragmented stretched sulfides and soft oxide inclusions (Group II-b) may work as the lubrication and protective layer for the tool during the machining operation. These Group II inclusions can also be beneficial for the deformation and sliding of metal layers relative to each other (for instance, in the secondary deformation zone) in chips during machining.

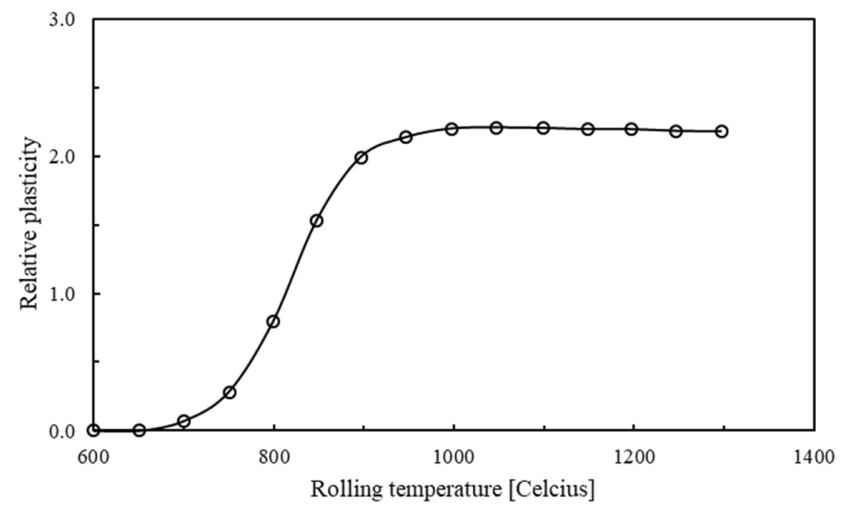

Fig. 8. Typical relative plasticity (ratio between the average effective strain of the inclusion and the average effective strain of the steel matrix) of $\mathrm{CaO}-\mathrm{Al}_{2} \mathrm{O}_{3}-\mathrm{SiO}_{2}$ inclusions at a rolling speed of $200 \mathrm{~mm} / \mathrm{s}^{28}$ ) 
Table 4. Deformation of different soft non-metallic inclusions (MnS and SO) in chips, depending on the deformation and temperature conditions.

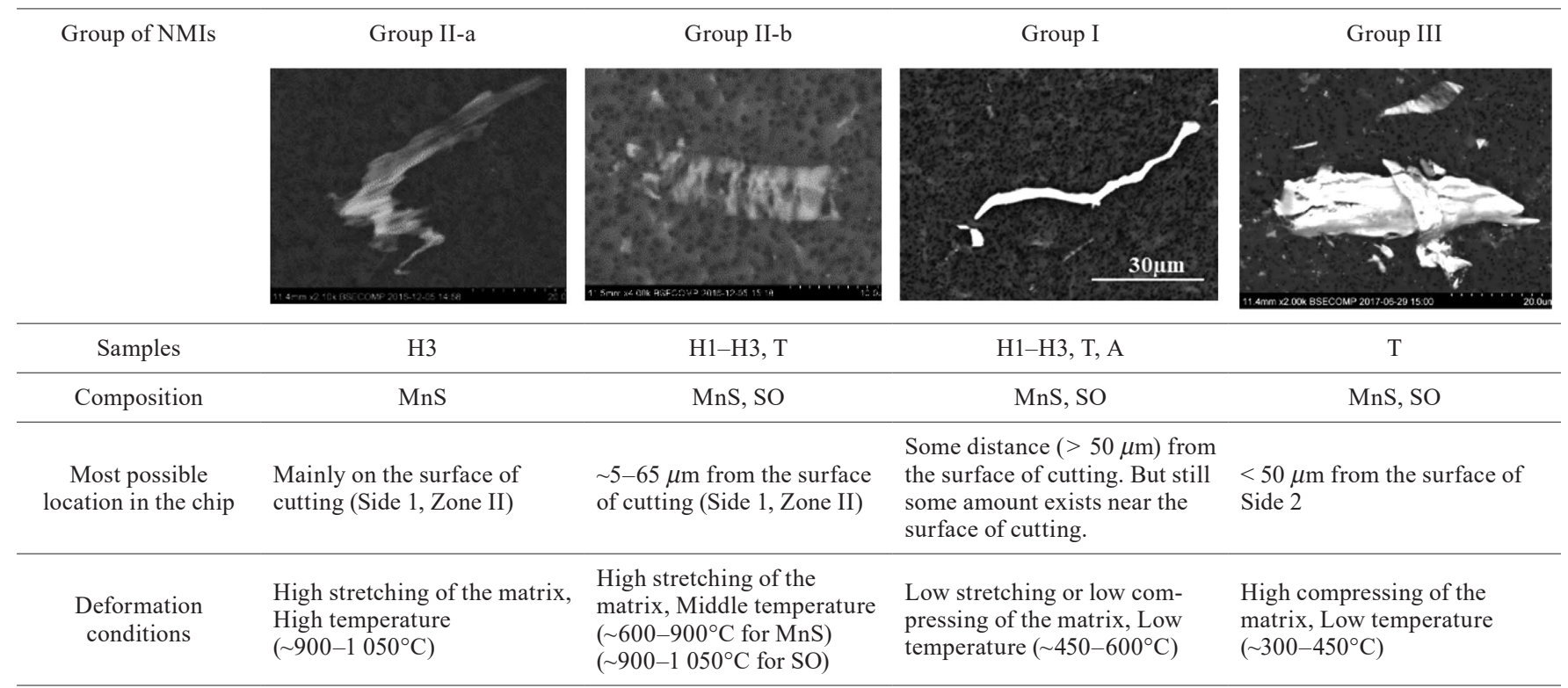

The sulfide and soft oxide inclusions of Group I, which look similar to those inclusions found in the reference $\mathrm{A}$ steel sample before machining, were observed in all investigated samples. However, most of these inclusions (up to $46 \%)$ were observed in the H1 sample $\left(D_{\text {dis }} \sim 65 \mu \mathrm{m}\right)$, whereas the samples $\mathrm{H} 2$ and $\mathrm{H} 3$ contained only about 30 , and $20 \%$ of those, respectively. This can be explained by the much lower deformation and temperature $\left(\sim 450-600^{\circ} \mathrm{C}\right)$ ranges of the metal matrix in chips at distances more than $50 \mu \mathrm{m}$ from the cutting surface.

Brittlely fractured sulfides and SO (Group III inclusions, about 16\%) were found only in Sample T (Side 2, $D_{\text {dis }} \sim 47$ $\mu \mathrm{m})$, which had experienced a relatively high compression deformation at low temperatures $\left(\sim 300-450^{\circ} \mathrm{C}\right)$. These inclusions and brittlely fractured $\mathrm{HO}$ inclusions can promote the formation of stress concentrations, initiation and propagation of cracks, as well as the destruction of the chip metal matrix. It should be pointed out that Group III sulfides and SO inclusions were not observed in the $\mathrm{H} 1, \mathrm{H} 2$, and $\mathrm{H} 3$ samples because the metal matrix on Side 1 of the chips mostly experienced higher temperatures.

It was found in this study that the deformation and behavior of HO inclusions were not affected by the location and temperature distribution in the chip. The HO inclusions act as a rigid particle at the cutting conditions of this study. The frequency of these inclusions varied from $20 \%$ up to $25 \%$, and most of those (up to $16 \%$ ) in the H1-H3 samples corresponded to undeformed Group I inclusions.

\section{Conclusion}

The focus of this study was to investigate non-metallic inclusions (NMIs) in the stainless steel before (reference steel sample) and after machining (in steel chips). The electrolytic extraction (EE) technique was used to extract nonmetallic inclusions in their original morphologies from steel samples. This technique made it possible to investigate the NMIs as three-dimensional objects on film filters by using
SEM combined with EDS. The characteristics of NMIs in steel samples and chips have been systematically investigated and compared in different chip zones and distances from the cutting surface. The main results are summarized as follows:

(1) It is advantageous to use electrolytic extraction to investigate extremely deformed NMIs in chips compared to using conventional two-dimensional methods. The EE method made it possible not to destroy the fragile morphologies of the extremely thin film-like MnS, fragmented stretched sulfides and SO inclusions, and cracked HO inclusions. The qualitative and quantitative information obtained by using the EE method, especially the characteristics of NMIs in the secondary deformation zone, will be helpful in studying the roles of NMIs during machining. These results, in turn, will help to explain the complex effect of the different NMIs on machining.

(2) The morphology of NMIs in stainless steel was significantly changed during machining. Overall, three different main shapes of NMIs were found: i) Group I inclusions having similar shapes to those inclusions found in the reference steel sample, ii) Group II stretched inclusions having very thin film-like (Group II-a) and fractured stretched morphologies (Group II-b), and iii) Group III brittlely fractured inclusions containing some cracks inside the inclusions. The total areas of $\mathrm{MnS}$ and $\mathrm{SO}$ inclusions in the secondary deformation zone of chip extracted from Sample H3 were increased significantly (up to 2-3 times) compared to that of the reference steel sample before the cutting test.

(3) The degree of deformation of $\mathrm{MnS}$ and soft oxide NMIs in different zones of the chips depends on the distances from the contact zone of the tool and the chip. The frequencies, average, and total areas of these different NMI groups are affected by the temperatures and metal matrix's deformation degrees in the chips' different zones during machining. For instance, Group II stretched sulfides and SO could be found mostly near the contact surface with the cut- 
ting tool. However, on the other side of the chip far from the tool, the frequency of Group III brittlely fractured inclusions of soft NMIs is larger compared to the surface contact with the tool. As a result, different inclusions can have different effects on the tool protection and chip breakability during machining. In addition, the HO inclusions were not affected by the temperature distribution at different locations, according to the studied set of parameters.

\section{Acknowledgments}

H. Du acknowledges the financial support from the China Scholarship Council (CSC), Jernkontoret and Stiftelsen Prytziska Fonden.

\section{REFERENCES}

1) G. M. Faulring and S. Ramalingam: Metall. Trans. A, 10 (1979), 1781. https://doi.org/10.1007/bf02811716

2) P. Leskovar and J. Grum: CIRP Ann., 35 (1986), 537. https://doi. org/10.1016/s0007-8506(07)60199-2

3) X. D. Fang and D. Zhang: Wear, 197 (1996), 169. https://doi. org/10.1016/0043-1648(96)06924-4

4) N. Åmmark and T. Björk: Wear, 368-369 (2016), 173. https://doi. org/10.1016/j.wear.2016.09.016

5) O. Bletton, R. Duet and P. Pedarre: Wear, 139 (1990), 179. https:// doi.org/10.1016/0043-1648(90)90044-b

6) L. Jiang, K. Cui and H. Hänninen: J. Mater. Process. Technol., 58 (1996), 160. https://doi.org/10.1016/0924-0136(95)02144-2

7) H. Opitz and W. König: Proc. 8th Int. M.T.D.R. Conf., (the University of Manchester Institute of Science and Technology), ed. by S. A. Tobias and F. Koenigsberger, Pergamon Press, Oxford, UK, (1968), 173. https://doi.org/10.1016/B978-0-08-003491-1.50013-7

8) H. S. Qi and B. Mills: Wear, 198 (1996), 192. https://doi.org/ 10.1016/0043-1648(96)80023-8

9) K. Ohgo, K. Nakajima and T. Awano: Wear, 40 (1976), 85. https:// doi.org/10.1016/0043-1648(76)90020-x

10) L. Sidjanin and P. Kovac: Mater. Sci. Technol., 13 (1997), 439. https://doi.org/https://doi.org/10.1179/mst.1997.13.5.439

11) N. Ånmark, A. Karasev and P. G. Jönsson: Materials, 8 (2015), 751. https://doi.org/10.3390/ma8020751

12) J. C. Hamann, V. Grolleau and F. Le Maître: CIRP Ann., 45 (1996), 87. https://doi.org/10.1016/s0007-8506(07)63022-4

13) Z. Li and D. Wu: J. Mater. Sci. Technol., 26 (2010), 839. https://doi. org/10.1016/s1005-0302(10)60134-x

14) E. Harju, S. Kivivuori and A. S. Korhonen: Surf. Coat. Technol., 112 (1999), 98. https://doi.org/10.1016/s0257-8972(98)00771-3

15) P. Hoier, A. Malakizadi, S. Friebe, U. Klement and P. Krajnik: Wear, 428-429 (2019), 315. https://doi.org/10.1016/j.wear.2019.02.024

16) A. Larsson and S. Ruppi: Mater. Sci. Eng. A, 313 (2001), 160. https:// doi.org/10.1016/s0921-5093(01)00964-9

17) A. Nordgren and A. Melander: Mater. Sci. Technol., 5 (1989), 940. https://doi.org/10.1179/mst.1989.5.9.940

18) Y. Kanbe, A. Karasev, H. Todoroki and P. G. Jönsson: Steel Res. Int., 82 (2011), 313. https://doi.org/10.1002/srin.201000141

19) D. Janis, A. Karasev, R. Inoue and P. G. Jönsson: Steel Res. Int., 86 (2015), 1271. https://doi.org/10.1002/srin.201400316

20) Y. Kanbe, A. Karasev, H. Todoroki and P. G. Jönsson: ISIJ Int., 51 (2011), 593. https://doi.org/10.2355/isijinternational.51.593

21) R. Inoue, S. Ueda, T. Ariyama and H. Suito: ISIJ Int., 51 (2011), 2050. https://doi.org/10.2355/isijinternational.51.2050

22) R. Inoue, K. Kiyokawa, K. Tomoda, S. Ueda and T. Ariyama: Proc. 8th Int. Workshop on Progress in Analytical Chemistry and Materials Characterisation in the Steel and Metal Industries (CETAS '11), (Luxembourg), Commission of the European Communities and the European Committee for the Study and Application of Analytical Work in the Steel Industry (CETAS), (2011), 118.

$23)$ R. Inoue, R. Kimura, S. Ueda and H. Suito: ISIJ Int., 53 (2013), 1906. https://doi.org/10.2355/isijinternational.53.1906

24) H. Du, A. Karasev, O. Sundqvist and P. Jönsson: Metals, 9 (2019), 74. https://doi.org/10.3390/met9010074

25) F. Kara, K. Aslantaş and A. Çiçek: Appl. Soft Comput., 38 (2016), 64. https://doi.org/10.1016/j.asoc.2015.09.034

26) R. M'Saoubi and H. Chandrasekaran: Int. J. Adv. Manuf. Technol., 56 (2011), 865. https://doi.org/10.1007/s00170-011-3257-y

27) T. J. Baker, K. B. Gave and J. A. Charles: Met. Technol., 3 (1976), 183. https://doi.org/10.1179/030716976803391656

28) C. Luo and U. Ståhlberg: J. Mater. Process. Technol., 114 (2001), 87. https://doi.org/10.1016/s0924-0136(01)00576-3

29) V. Ollilaien: Proc. Swedish Symp. on Non-Metallic Inclusions in Steel, Uddeholms AB, Hagfors, (1981), 429. 